\title{
Changes in Nutrient Biomarkers, Body Composition, and Burnout Symptoms in Collegiate Athletes across a Season
}

\author{
Tamara Hew-Butler ${ }^{1,2 *}$, Carrie Aprik ${ }^{2}$, Brigid Byrd ${ }^{1}$, Kristin Landis-Piwowar' ${ }^{2}$, Valerie Smith-Hale ${ }^{1}$, \\ Matthew VanSumeren ${ }^{1}$, Jordan Sabourin ${ }^{1}$, Gregory Byrd ${ }^{3}$, Jeffrey Martin ${ }^{1}$
}

1 Kinesiology, Health and Sport Studies, Wayne State University, Detroit, MI 48202 USA; tamara.hewbutler@wayne.edu; brigidbyrd@gmail.com; valerie.smith2@wayne.edu; msvansum@wayne.edu; jsabourin@wayne.edu; aa3975@wayne.edu

2 School of Health Science and Athletics Deptartment, Oakland University, Rochester, MI, 48309 USA; caprik@oakland.edu; landispi@oakland.edu

3 Internal Medicine Department, Mission Health, Asheville, NC, 28801 USA; gregory byrd@teamhealth.com

* Correspondence: tamara.hew-butler@wayne.edu; Tel.: 313-577-8130

\begin{abstract}
Adequate serum vitamin D and iron levels are thought to positively influence physical training adaptations and mood. The purpose of this prospective, observational, study was to investigate relationships between serum 25-OH vitamin $\mathrm{D}$ and serum ferritin levels with body composition and athlete burnout symptoms. Seventy-three collegiate athletes ( 49 female) from 7 indoor and outdoor sports were tested pre-season and post-season for: nutrient biomarkers (serum 25-OH vitamin $\mathrm{D}$ and serum ferritin) via venipuncture; body composition (total lean mass, bone mineral density/BMD, and \% body fat) via dual energy $\mathrm{x}$-ray absorptiometry (DXA) scans; and athlete burnout symptoms (post-season) via the athlete burnout questionnaire (ABQ). When male and female cohorts were combined, significant relationships were noted between pre-season serum $25-\mathrm{OH}$ vita$\min \mathrm{D}$ versus the change ( $\Delta$ : post-season minus pre-season) in both BMD ( $\mathrm{r}=-0.34 ; \mathrm{p}=0.0003)$ and $\%$ body fat $(\mathrm{r}=-0.28 ; \mathrm{p}=0.015)$. Serum ferritin $\Delta$ was significantly associated with lean mass $\Delta$ ( $\mathrm{r}=-$ $0.34 ; \mathrm{p}=0.003)$. For burnout symptoms, serum $25-\mathrm{OH}$ vitamin $\mathrm{D} \Delta$ significantly explained $20.6 \%$ of the variance for devaluation of sport in the male cohort only. Across time, serum $25-\mathrm{OH}$ vitamin $\mathrm{D}$ levels increased while serum ferritin levels decreased, non-significantly, in both males and females. Relationships between nutrient biomarkers and body composition were opposite of physiological expectations.
\end{abstract}

Keywords: vitamin D, ferritin, student-athletes, DXA scan

\section{Introduction}

The trend towards precision medicine [1] has fueled a more individualized approach towards precision athletic health and training. Assessing nutrient biomarkers, as a potential driver of favorable adaptations in muscle strength [2], performance [3], and mood [4], has fast become standardized practice in elite athlete screenings [5-7]. However, the development of normative values which promote health and peak performance, in the context of both sex and sport, remain to be elucidated.

Blood nutrient biomarkers which reflect vitamin D [6,8-13] and iron [3,5,7,14-16] status are commonly measured in athletes, particularly collegiate athletes [6,7,9-12,14]. Vitamin D (typically assessed as serum $25-\mathrm{OH}$ vitamin D measurement) has emerged as a potential ergogenic aid [2], reducing muscle damage [17], stress fractures [18], and frequent illness [13]. Similarly, correction of low iron levels (typically assessed as serum ferritin measurement) has been shown to improve endurance performance [3], subjective measures of performance [19], and fatigue [16] in female athletes. The downside of blood 
biomarker measurement, however, is cost. For example, the average annual cost to screen athletes at one National Collegiate Athletic Association Division 1 (NCAA D1) Institution for serum 25-OH vitamin $\mathrm{D}$ was estimated at $\$ 7250$ (average cost $\$ 51-100$ per laboratory draw) [6] while the estimated cost for serum ferritin measurement was $\$ 4248$ ( $\$ 32$ per laboratory draw) [7].

Another commonly utilized training outcome measure is body composition. Favorable training adaptations include increasing lean [20] and bone [21] mass while decreasing fat mass [20] across a competitive season. Unhealthy adaptations in response to over-training, inadequate nutrition, or relative energy deficiency in sport (RED-S), often manifest as decreased lean [22] or bone [23] mass which, in turn, precedes injury and illness [22-25]. Favorable relationships between nutrient blood biomarkers (such as vitamin D and iron) and body composition variables would thereby underscore the importance of nutrient screening and supplementation, in collegiate athletes, in future.

In addition to markers of physical health, relationships between serum 25-OH-vitamin $\mathrm{D}$ and ferritin on athlete mental health remain underexplored. Evidence suggests that low serum 25-OH vitamin $\mathrm{D}$ and ferritin levels are inversely related to depression scores $[26,27]$ in university students. However, relationships between serum $25-\mathrm{OH}$ vitamin D and ferritin with burnout symptoms in athletes have yet to be examined.

Therefore, the primary aim of this preliminary investigation was to prospectively investigate (pre- and post-season) relationships between serum $25-\mathrm{OH}$ vitamin $\mathrm{D}$ and serum ferritin levels with body composition variables in a cohort of indoor and outdoor NCAA D1 collegiate athletes. A secondary aim was to explore relationships between serum 25$\mathrm{OH}$ vitamin $\mathrm{D}$ and ferritin levels with athletic burnout symptoms.

\section{Materials and Methods}

Student-athletes from a midwestern National Collegiate Athletic Association Division 1 (NCAA D1) University (latitude $42.7^{\circ} \mathrm{N}$ ) were recruited to participate in this prospective, observational, study. Participants from seven different fall and winter sports teams (men and women's cross country/XC, swimming, and basketball plus women's soccer) were recruited and signed written informed consent to participate in this Institutional Review Board (IRB) approved study (Oakland University IRB\#778936). Athletes presented to the lab both pre-season (September) and post-season (men and women's XC in December; women's soccer in January; men and women's basketball and swimming teams in April). Athletes were asked to refrain from exercise and eating (other than water, when thirsty) for 4-hours prior to each laboratory visit. Athletes were also instructed to wear compression shorts (plus sport bras for females), without any metal, for the dual energy x-ray absorptiometry (DXA) scans. The following procedures were performed:

2.1 Blood biomarkers: Serum 25-OH vitamin D and serum ferritin were assessed by a local hospital laboratory (Cobas E Immunoassay, Ascension-Crittenton Hospital, Rochester, Michigan), following venipuncture in a supine position. All separated serum specimens were sent to the hospital laboratory within 12-hours of venipuncture. The diagnostic threshold for serum $25-\mathrm{OH}$ vitamin $\mathrm{D}$ insufficiency was $\leq 30 \mathrm{ng} / \mathrm{mL}[8,28]$ while serum ferritin insufficiency was defined as any value $\leq 35 \mathrm{ng} / \mathrm{mL}[29]$.

2.2 Total body composition: Height and weight were measured in compression clothes, without shoes or socks, on a stadiometer with a weight beam scale. Total body lean, fat and bone mass were measured using a whole-body DXA scan (Horizon A, software version 13.6.0.5, TBAR102 NHANES BCA calibration, Hologic ${ }^{\mathrm{TM}}$, Bedford, MA). All DXA scans were performed following standardized protocols, outlined in the product user manual [30]. Athletes who were taller than the scan table parameters were positioned with their feet outside of the scan area, both times (standardized). We chose to report total bone mass as bone mineral density (BMD in $\mathrm{g} / \mathrm{cm}^{2}$ ) and total fat mass as a percentage (body fat $\%)$ to standardize these variables across sex, sport, and body weight. However, we reported total lean mass in kilograms to reflect size and metabolic demand differences. 
2.3 Post-season burnout assessment: A 15-question athlete burnout questionnaire (ABQ) was completed, in the laboratory, at the post-competitive season timepoint only [31]. Each question was measured on a 5-point Likert scale, with 1 representing "almost never" and 5 representing "almost always". Subscales of the ABQ include devaluation of sport, emotional and physical exhaustion, and reduced sense of accomplishment which have been previously validated in a cohort of collegiate athletes [31].

2.4 Statistical analyses: Paired t-tests were utilized to compare pre-season to post-season changes in anthropometric, body composition and blood biomarker variables. Repeated-measures ANOVA analyses were utilized to assess time (pre- to post-season) and team (sports) differences, plus possible interactions between time vs. team (F-value). Linear relationships between variables were assessed using Pearson's $r$ for continuous variables (blood biomarkers and body composition) and Spearman's rank-order correlations for categorical variables (ABQ). The effect size for each correlation coefficient $(r)$ was also interpreted using Cohen's $d$ whereas: $r=0.2$ represented a small effect; $r=0.5$ represented a medium effect; and $\mathrm{r}=0.8$ represented a large effect [32].

The pre-season to post-season change for all continuous variables were denoted by the symbol " $\Delta$ ", which reflected the mathematical calculation of "post-season minus preseason". Therefore, any positive $\Delta$ value represented an increase while any negative $\Delta$ value represented a decrease in the stated variable across time. All data expressed as mean $\pm \mathrm{SD}$, with statistical significance set a priori at $\mathrm{p}<0.05$.

\section{Results}

Seventy-three student-athletes (49 female) completed both pre-season and post-season testing. Pre-season demographic and anthropometric data for both male and female cohorts, separated further into sports teams, are reported in Table 1.

Table 1: Student-athlete demographics by sex and sports team $(X C=$ cross country; $B M I=b o d y$ mass

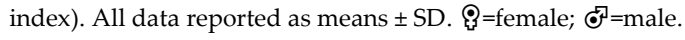

\begin{tabular}{|c|c|c|c|c|}
\hline $\begin{array}{l}\text { Team } \\
(N=73)\end{array}$ & $\begin{array}{c}\text { Age } \\
\text { (years) }\end{array}$ & $\begin{array}{l}\text { Height } \\
\text { (m) }\end{array}$ & $\begin{array}{c}\text { Weight } \\
(\mathrm{kg})\end{array}$ & $\begin{array}{c}\text { BMI } \\
\left(\mathrm{kg} / \mathrm{m}^{2}\right)\end{array}$ \\
\hline $\begin{array}{l}9 \times C \\
(n=16)\end{array}$ & $19.4 \pm 1.5$ & $1.64 \pm 0.1$ & $56.6 \pm 4.9$ & $20.8 \pm 1.8$ \\
\hline$\underset{(n=9)}{7 \times C}$ & $20.3 \pm 0.9$ & $1.80 \pm 0.1$ & $68.8 \pm 6.9$ & $21.3 \pm 0.9$ \\
\hline $\begin{array}{c}\text { Pswim } \\
(n-12)\end{array}$ & $19.6 \pm 1.1$ & $1.70 \pm 0.1$ & $67.2 \pm 5.8$ & $23.2 \pm 2.1$ \\
\hline$\underset{(n=6)}{\text { Swim }}$ & $20.7 \pm 1.2$ & $1.84 \pm 0.1$ & $78.5 \pm 5.2$ & $23.3 \pm 1.6$ \\
\hline $\begin{array}{c}\text { Basketball } \\
(n=10)\end{array}$ & $19.7 \pm 1.4$ & $1.76 \pm 0.1$ & $75.1 \pm 12.0$ & $24.3 \pm 3.4$ \\
\hline$\underset{(n=9)}{\substack{\text { Basketball } \\
(1)}}$ & $20.1 \pm 1.5$ & $1.96 \pm 0.1$ & $94.5 \pm 14.3$ & $24.6 \pm 2.8$ \\
\hline $\begin{array}{c}\text { Q } \\
\text { Soccer } \\
(n=11)\end{array}$ & $19.5 \pm 1.2$ & $1.69 \pm 0.1$ & $64.9 \pm 14.4$ & $22.6 \pm 3.6$ \\
\hline$\underset{(n=49)}{\text { C COMBINED }^{2}}$ & $19.5 \pm 1.3$ & $1.69 \pm 0.1$ & $64.8 \pm 11.5$ & $22.5 \pm 2.0$ \\
\hline of COMBINED & $20.3 \pm 0.1$ & $1.87 \pm 0.1$ & $80.9 \pm 15.0$ & $23.0 \pm 2.4$ \\
\hline
\end{tabular}

The pre-season and $\Delta$ in body composition variables for both male and female cohorts, separated further by sports team, are reported in Table 2. No statistically significant differences (pre-season vs. post-season; paired t-test analyses) were noted for any body composition measure across time for any team. Repeated measures ANOVA analyses did 
not detect any significant interactions between time vs. team for any body composition variable.

Table 2: Pre-season and change ( $\Delta$ : post-season minus pre-season) in total body fat $(\%)$, bone mineral density (BMD), and lean mass in student-athletes by sex and sports team $(X C=$ cross country. $\mathrm{BMD}=$ bone mineral density). All data reported as means $\pm \mathrm{SD}$. $\&=$ female; $\odot=$ male

\begin{tabular}{|c|c|c|c|c|c|c|}
\hline $\begin{array}{c}\text { Team } \\
(N=73)\end{array}$ & $\begin{array}{c}\text { Pre } \\
\text { Body Fat } \\
(\%) \\
\end{array}$ & $\begin{array}{c}\Delta \\
\text { Body Fat } \\
(\%) \\
\end{array}$ & $\begin{array}{c}\text { Pre } \\
\text { BMD } \\
\left(\mathrm{g} / \mathrm{cm}^{2}\right)\end{array}$ & $\begin{array}{c}\Delta \\
\text { BMD } \\
\left(\mathrm{g} / \mathrm{cm}^{2}\right)\end{array}$ & $\begin{array}{c}\text { Pre } \\
\text { Lean Mass } \\
(k g)\end{array}$ & $\begin{array}{c}\Delta \\
\text { Lean Mass } \\
(\mathrm{kg})\end{array}$ \\
\hline $\begin{array}{l}9 \times C \\
(n=16)\end{array}$ & $18.7 \pm 3.1$ & $-0.8 \pm 1.1$ & $1.08 \pm 0.06$ & $-0.00 \pm 0.02$ & $43.7 \pm 4.3$ & $-0.4 \pm 0.9$ \\
\hline$\underset{(n=9)}{\sigma^{X C}}$ & $8.5 \pm 1.1$ & $-0.1 \pm 0.8$ & $1.22 \pm 0.05$ & $-0.01 \pm 0.01$ & $59.4 \pm 6.1$ & $-0.3 \pm 0.9$ \\
\hline $\begin{array}{c}\text { Swim } \\
(n-12)\end{array}$ & $21.2 \pm 3.8$ & $-1.7 \pm 1.8$ & $1.08 \pm 0.07$ & $0.00 \pm 0.02$ & $49.0 \pm 3.0$ & $1.8 \pm 1.3$ \\
\hline$\underset{(n=6)}{\operatorname{SSwim}}$ & $12.0 \pm 2.4$ & $-1.3 \pm 1.7$ & $1.17 \pm 0.07$ & $0.00 \pm 0.01$ & $66.0 \pm 5.5$ & $0.5 \pm 2.1$ \\
\hline $\begin{array}{l}\text { Basketball } \\
(n=10)\end{array}$ & $18.2 \pm 5.1$ & $-0.7 \pm 1.1$ & $1.19 \pm 0.09$ & $0.01 \pm 0.02$ & $56.1 \pm 5.9$ & $-0.6 \pm 1.9$ \\
\hline $\begin{array}{l}\text { Basketball } \\
(n=9)\end{array}$ & $10.7 \pm 3.0$ & $0.8 \pm 1.4$ & $1.37 \pm 0.09$ & $0.02 \pm 0.02$ & $77.8 \pm 9.1$ & $-1.3 \pm 1.4$ \\
\hline $\mathbf{P}_{\substack{(n=11) \\
\text { Soccer }}}$ & $19.9 \pm 5.0$ & $0.2 \pm 1.5$ & $1.09 \pm 0.07$ & $0.01 \pm 0.01$ & $48.7 \pm 6.5$ & $-0.8 \pm 1.5$ \\
\hline $\begin{array}{l}\text { COMBINED } \\
(n=49)\end{array}$ & $19.5 \pm 4.2$ & $-0.8 \pm 1.5$ & $1.10 \pm 0.08$ & $0.00 \pm 0.02$ & $48.7 \pm 6.6$ & $-0.2 \pm 1.6$ \\
\hline $\begin{array}{l}\text { COMBINED } \\
(n=24)\end{array}$ & $10.2 \pm 2.6$ & $-0.1 \pm 1.5$ & $1.27 \pm 0.11$ & $0.01 \pm 0.02$ & $67.9 \pm 10.8$ & $0.3 \pm 3.8$ \\
\hline
\end{tabular}

Pre-season and post-season biomarker measurements for serum 25-OH-vitamin D in males (1a) and females (1b) and serum ferritin concentrations in males (1c) and females (1d) are depicted in Figure 1. No statistically significant differences (pre-season vs. postseason; paired t-test analyses) were noted for any biomarker measure for any team. Repeated measures ANOVA analyses detected a significant interaction between time vs. team for serum ferritin in the female cohort only $(\mathrm{F}=4.2 ; \mathrm{p}=0.03)$.

With specific regards to biomarker changes in male participants, the mean serum 25 $\mathrm{OH}$ vitamin $\mathrm{D}$ levels in the male basketball team was significantly lower than the mean value for male cross country $(X C)$ and swim teams both pre- and post-season (Figure 1a). Thirty-eight percent of all male athletes were $25-\mathrm{OH}$ vitamin $\mathrm{D}$ insufficient pre-season increasing to $50 \%$ at post-season. Two male athletes ( $8 \%$ ) were diagnosed with serum ferritin insufficiency pre-season, while only one male athlete demonstrated serum ferritin insufficiency post-season (4\%).

With specific regards to biomarker changes in female participants, no significant time or team differences in mean 25-OH vitamin D levels were observed (Figure 1b). Twentyfour percent of female athletes were $25-\mathrm{OH}$ vitamin $\mathrm{D}$ insufficient pre-season increasing to $35 \%$ at post-season. A significant interaction effect (time versus team) was noted for serum ferritin for females, with the female soccer players demonstrating lower pre- to post-season changes compared with the XC, swim, and basketball teams (Figure 1d). Fiftyseven percent of all female participants were diagnosed with serum ferritin insufficiency pre-season which improved to $31 \%$ post-season. 

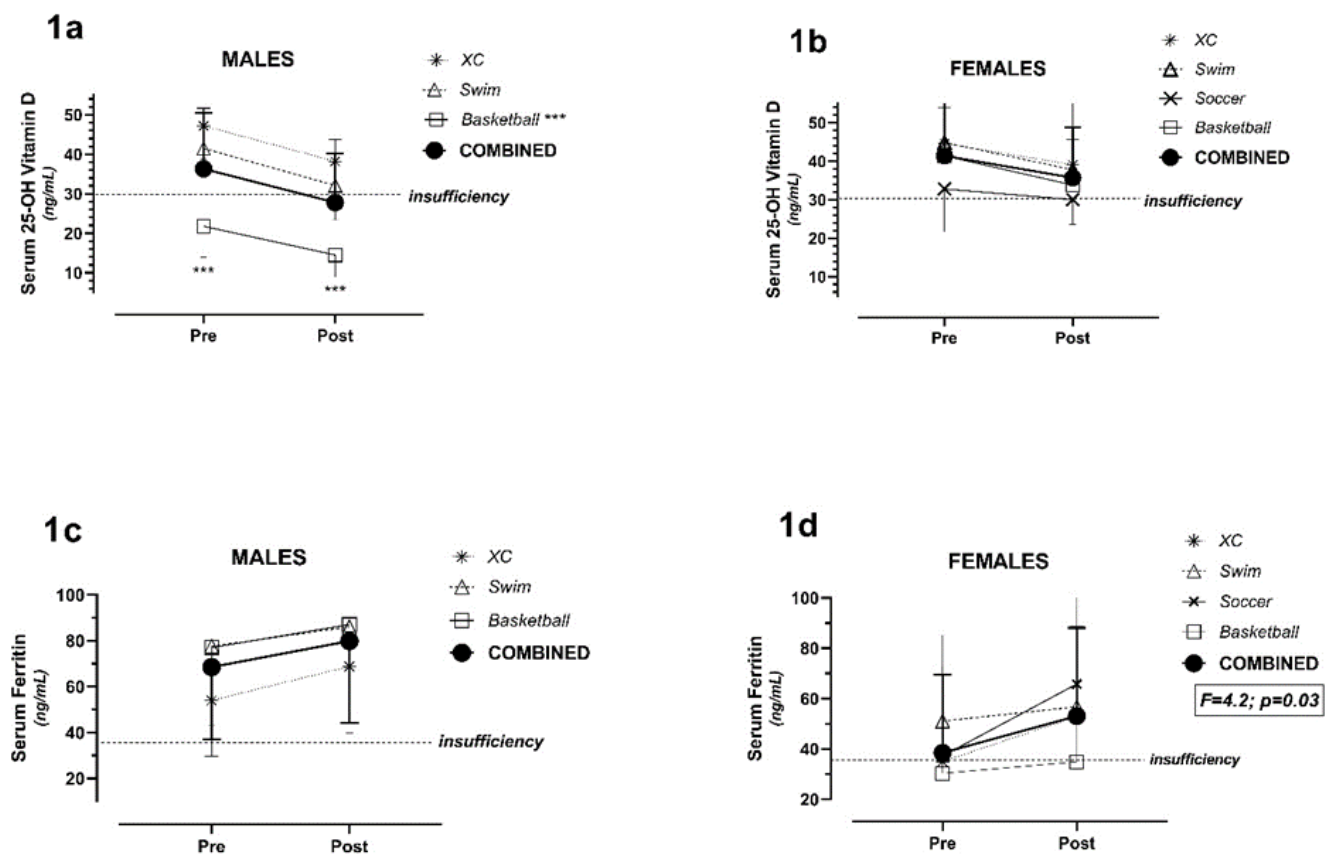

*** $p<0.001$ between Basketball vs. XC and Swim, both pre-season and post-season (Figure 1a) $p<0.05$ between Soccer vs. Swim and Basketball for $\Delta$ serum ferritin (Figure 1d)

Figure 1: Pre-season to post-season changes in serum 25-OH Vitamin D and serum ferritin concentrations by sex and sports team.

With regards to correlation analyses, when both male and female student-athletes were combined $(\mathrm{N}=73)$, significant negative correlations were observed between pre-season 25-OH vitamin D levels with both BMD $\Delta$ (Figure 2a) and \% body fat $\Delta$ (Figure $2 \mathrm{~b}$ ). Serum ferritin $\Delta$ was also inversely related with lean mass $\Delta$, across the competitive season (Figure 2c). All three correlation coefficients $(\sim r=0.3)$ suggests that the effect sizes of these relationships were small, despite meeting the criteria for statistical significance [32]. No other significant correlations were noted between serum 25-OH-D $\Delta$ vs. lean mass $\Delta(\mathrm{r}=-$ $0.00 ; \mathrm{p}=0.94)$, BMD $\Delta(\mathrm{r}=0.04 ; \mathrm{p}=0.74)$ or $\%$ body fat $\Delta(\mathrm{r}=-0.03 \mathrm{p}=0.80)$ or between serum ferritin $\Delta$ vs. BMD $\Delta(\mathrm{r}=0.06 ; \mathrm{p}=0.63)$ or $\%$ body fat $\Delta(\mathrm{r}=0.17 ; \mathrm{p}=0.13)$. 

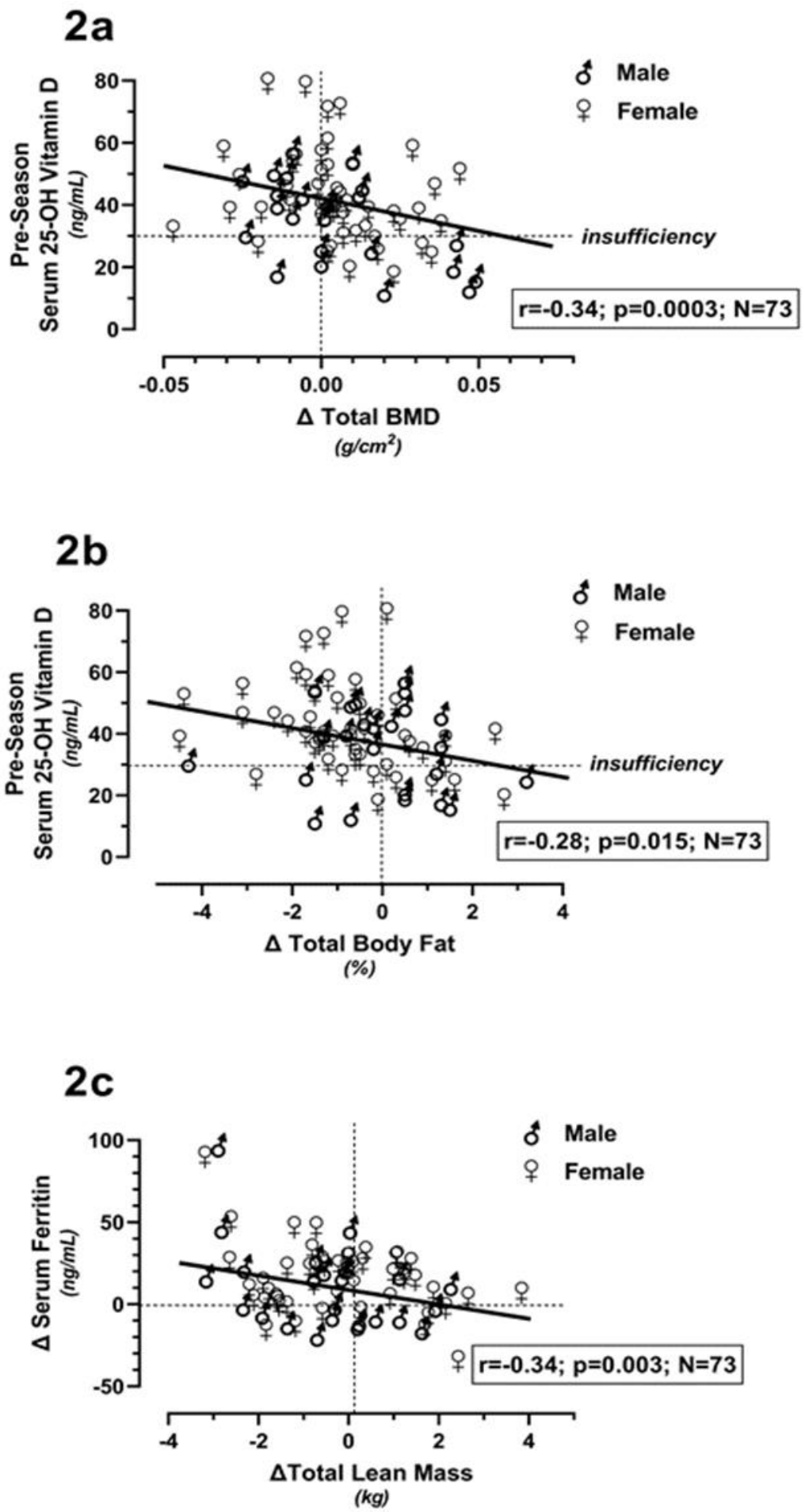

Figure 2: Statistically significant correlations between pre-season serum 25-OH-Vitamin D and changes ( $\triangle$ : post-minus pre-season change) in bone mineral density $(B M D)(2 a)$ and total body fat $\%(4 b)$ as well as between changes in serum ferritin and changes in total body lean mass (2c) when all athletes were combined $(N=73)$.

When the male cohort $(n=24)$ was analyzed separately, stronger negative correlations were noted between pre-season $25-\mathrm{OH}$ vitamin $\mathrm{D}$ versus all three major body composition variables, pre-season (Figure $3 a, 3 b$, and $3 c$ ) and with BMD $\Delta$ (Figure 3d). The correlation coefficients suggested a moderate effect [32] among 25-OH vitamin D levels versus body composition variables. Of particular note, male basketball players paradoxically 
demonstrated the lowest 25-OH vitamin D blood biomarker levels, of all athletes tested, but had the most favorable body composition parameters recorded (i.e. highest BMD and lean mass, with the lowest body fat percentage).

\section{$3 a$}

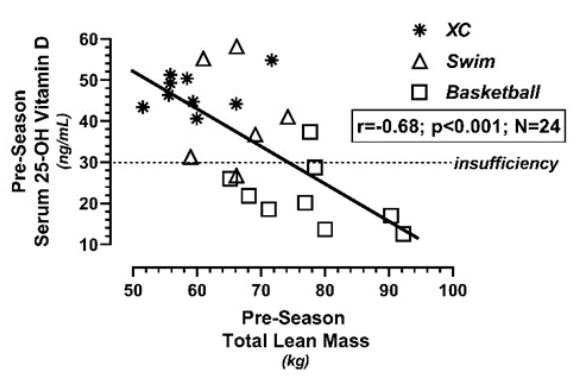

$3 c$

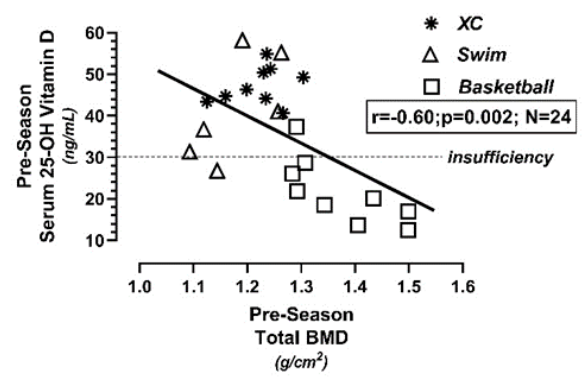

3b

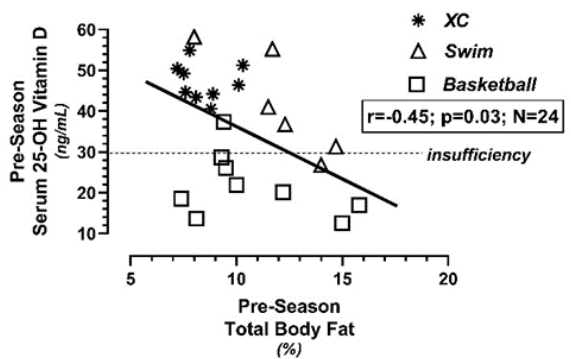

$3 d$

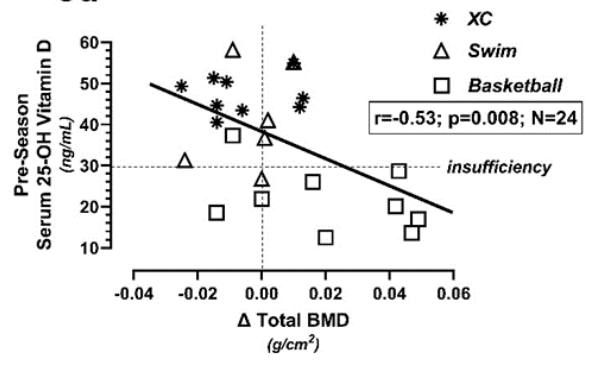

Figure 3: Statistically significant correlations between pre-season 25-OH-Vitamin D and pre-season total body lean mass (3a), body fat \% (3b), bone mineral density $(B M D)(3 c)$, and changes in $B M D(3 d)$ for the male cohort only $(n=24)$.

When the female cohort $(\mathrm{n}=49)$ was analyzed separately, serum ferritin $\Delta$ was negatively correlated with lean mass $\Delta$ (Figure 4 a) and positively correlated with \% body fat $\Delta$ (Figure 4b). The correlation coefficients suggested small-to-moderate effect sizes [32]. 

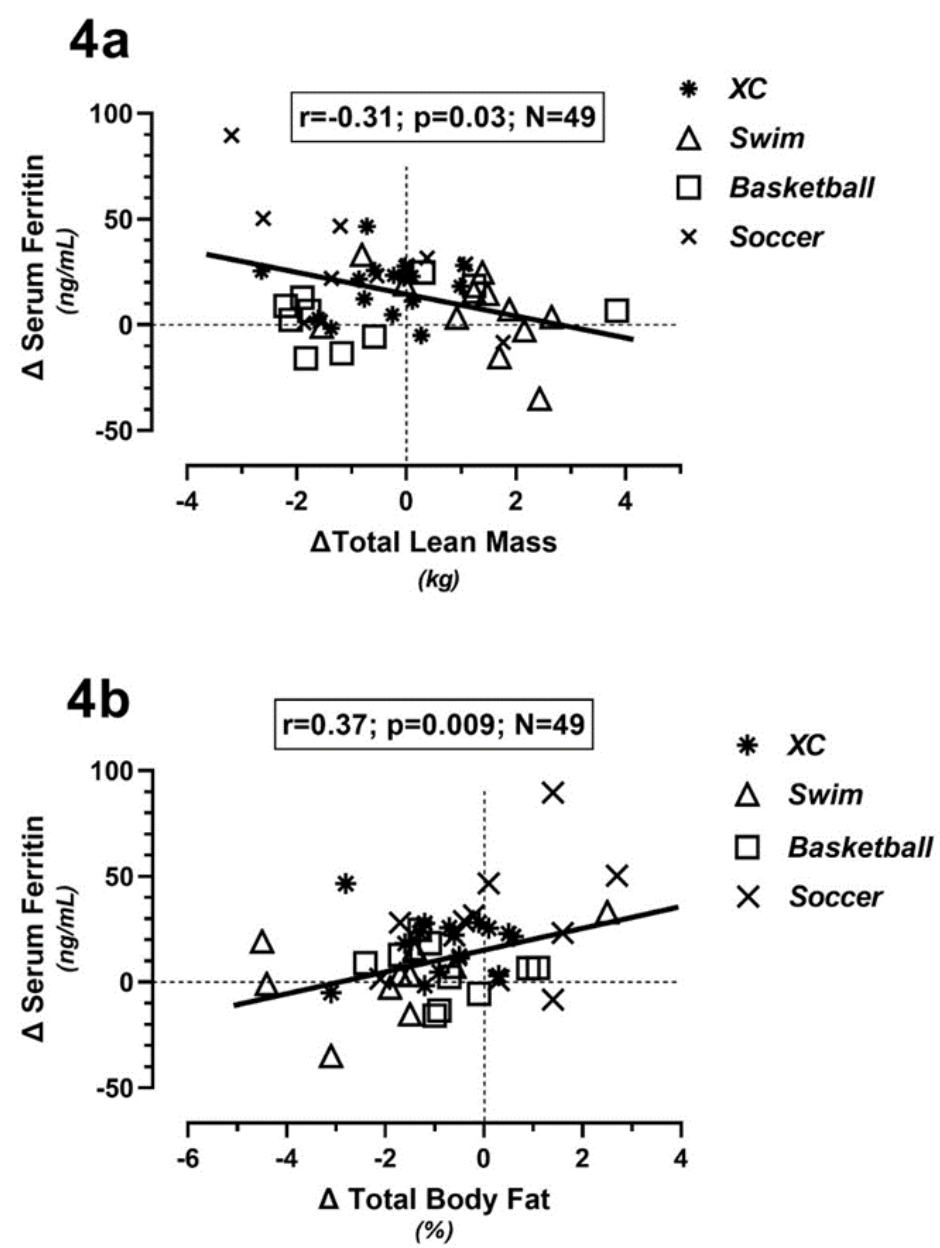

Figure 4: Statistically significant correlations between changes ( $\Delta$ : post- minus pre-season change) in serum ferritin concentration and changes in total body lean mass (4a) and changes in total body fat $\%(4 b)$ for the female cohort only $(n=49)$.

For the athlete burnout symptoms analyses, we conducted three linear regression analyses using the entire cohort ( $\mathrm{N}=72$; one athlete did not complete the post-season $\mathrm{ABQ})$. None of the three equations were significant, using either serum 25-OH vitamin $\mathrm{D} \Delta(p=$ $0.78)$ or serum ferritin $\Delta(p=0.69)$ to predict each ABQ subscale. When analyses were separated by sex, neither serum $25-\mathrm{OH}$ vitamin $\mathrm{D} \Delta(p=0.57)$ nor serum ferritin $\Delta(p=.57)$ predicted athlete burnout symptoms in females.

However, a significant decrease in serum $25-\mathrm{OH}$ vitamin $\mathrm{D} \Delta(-8.4 \pm 4.3 \mathrm{ng} / \mathrm{mL}) \mathrm{did}$ significantly predict and explain $20.6 \%$ of the variance of male athlete perceptions of devaluation of sport $(p<0.05)$. Additionally, pre-season serum ferritin levels $(68.5 \pm$ $31.4 \mathrm{ng} / \mathrm{mL}$ ) explained $16 \%$ of the variance of male athlete perceptions of physical and emotional exhaustion from sport $(p \leq 0.05)$. Additionally, pre-season serum ferritin and athlete burnout $(r=.41: p<0.05)$, post-season serum ferritin levels and athlete burnout $(r=$ $.36 ; \mathrm{NS})$, and $25-\mathrm{OH}$ vitamin $\mathrm{D} \Delta$ and athlete burnout $(r=.41 ; \mathrm{p}<0.05)$ were significant.

\section{Discussion}

Serum 25-OH vitamin D levels decreased in our cohort during the competitive season, for both male and female student-athletes, in both indoor (swimming, basketball) and outdoor (XC and soccer) sports (Figure 1a and 1b). A similar seasonal decline was documented in 47 indoor and outdoor University athletes, living in the United Kingdom (51.2을 $\mathrm{N}$ ), tested in Fall (pre-season) and Spring (post-season) [33]. Although serum 25-OH vitamin D $\Delta$ was not statistically significant in the overall cohort in the present study, post- 
season $25-\mathrm{OH}$ vitamin $\mathrm{D}$ levels were lower in male vs. female athletes $(27.8 \pm 12.4 \mathrm{ng} / \mathrm{mL}$ vs. $35.7 \pm 13.1 \mathrm{ng} / \mathrm{mL} ; \mathrm{p}=0.01)$. This sex difference has been verified in NCAA D1 athletes tested elsewhere [9] and of unclear biological or performance significance.

The low serum 25-OH vitamin D levels seen in our male athletes were largely driven by the male basketball players, all of which were classified as vitamin D insufficient postseason (Figure 1a). Low 25-OH vitamin D levels in male basketball players has been verified in the literature $[8,10,34]$, with dark skin color $[9,10,35]$ and limited sunlight exposure $[36,37]$ being the most biologically plausible explanation for this sports-specific finding.

Paradoxically, those student-athletes with the lowest serum $25-\mathrm{OH}$ vitamin $\mathrm{D}$ levels demonstrated the largest BMD increases across the season (Figure 2a). This significant inverse relationship between pre-season $25-\mathrm{OH}$ vitamin $\mathrm{D}$ and $\mathrm{BMD} \Delta$ was physiologically unexpected, given the interactive role vitamin D plays in enabling calcium mobilization and subsequent bone mineralization [28,38]. However, an inverse relationship between 25-OH vitamin D versus BMD has been documented previously in collegiate basketball players [10], which suggests that physical training may play a larger stimulatory role in bone formation [21] than isolated serum 25-OH vitamin D levels which warrants further scientific and temporal clarification.

Our investigation also demonstrated a significant inverse relationship between preseason $25-\mathrm{OH}$ vitamin $\mathrm{D}$ and $\%$ body fat $\Delta$ (Figure $2 \mathrm{~b}$ ). This negative relationship has been previously documented in a cross-sectional investigation of 42 collegiate athletes tested in the Fall [39]. In that study, the authors hypothesized that increased fat stores sequestered vitamin D away from the circulation [39]. Although vitamin D is a fat soluble vitamin, other cross-sectional studies performed on collegiate female indoor athletes [11], or a longitudinal (pre- to post) study performed on collegiate basketball players, found no significant correlations between $25-\mathrm{OH}$ vitamin $\mathrm{D}$ and body fat [10].

Of note, significant relationships between serum 25-OH vitamin D and body composition variables were largely present in our male, but not female, cohort (Figure 3). Fifty percent of male athletes and 35\% of female athletes, in the present study, were vitamin D insufficient post-season. No significant relationships were noted between any body composition variable and serum $25-\mathrm{OH}$ vitamin $\mathrm{D}$ in our female cohort. This lack of relationship between body composition and serum 25-OH levels in females has been demonstrated previously in a cohort of 36 collegiate female athletes [11] and of unclear physiological relevance.

The male cross country $(X C)$ runners in the current study, tended to have the highest serum 25-OH vitamin D levels, presumably from enhanced sunlight exposure during outdoor training and competition compared with indoor sport athletes such as swimmers and basketball players [13]. However, the higher absolute serum 25-OH vitamin D levels were not associated with higher BMD (Figure 3c and 3d), lean mass (Figure 3a), or fat percentage (Figure $3 b$ ) compared with swimmers or basketball players. These cross-sectional relationships highlight the complexity of assigning "peak" performance serum 25$\mathrm{OH}$ vitamin D thresholds, such as the $40 \mathrm{ng} / \mathrm{mL}$ threshold proposed for athletes [2], across a variety of sports. For example, male basketball players may function optimally within the $12-20 \mathrm{ng} / \mathrm{mL}$ normal range threshold recommended for bone health by the National Academy of Medicine [40] while other athletes may not [2]. Although screening for serum $25-\mathrm{OH}$ vitamin D remains popularized in elite athletes $[6,8,12]$, evidence to support general population screening for vitamin D deficiency remains inconclusive [41].

In contrast to the pre- to post-season decreases in serum $25-\mathrm{OH}$ vitamin $\mathrm{D}$ seen in the present study, increases in serum ferritin levels were seen across the season for all sports teams. Serum ferritin levels were significantly lower in female vs. male athletes both preseason $(38.5 \pm 3.0$ vs. $68.5 \pm 31.5 \mathrm{ng} / \mathrm{mL} ; \mathrm{p}=0.0002)$ and post-season (53.1 \pm 35.0 vs. $79.9 \pm$ $35.8 \mathrm{ng} / \mathrm{mL} ; \mathrm{p}=0.003$ ), due to increased blood losses (menses) in pre-menopausal females $[3,42]$. Student-athletes meeting the threshold for serum ferritin insufficiency $(\leq 35 \mathrm{ng} / \mathrm{mL})$ pre-season ( $57 \%$ of females and $8 \%$ of males) were counseled by the team nutritionist to increase iron ingestion through diet and self-supplementation as supplements were not provided (or prescribed) by the Athletic department. With that said, it was interesting to 
note that serum ferritin levels increased across time in the male cohort who were not counseled to increase iron intake. This unexpected increase in serum ferritin across both time and sport highlights the complexity of utilizing serum ferritin as a singular marker of tissue (mainly liver) iron stores, as serum ferritin is also an acute phase inflammatory marker [43]. Thus, increases in serum ferritin, as a measure of tissue iron stores across a competitive season, may be confounded by training or competition-induced inflammation as previously verified in athletes after endurance races $[29,44]$. The contributions of inflammation to increased serum ferritin levels (non-related to iron storage levels) thereby warrants further investigation using additional inflammatory markers such as hepcidin [3], C-reactive protein and interleukin-6 [44] in future athlete studies.

Serum ferritin $\Delta$ levels were inversely related to lean mass $\Delta$, when all athletes were combined (Figure 2c). The negative direction of this relationship suggests that those athletes who gained the most lean mass over the season demonstrated the steepest declines in serum ferritin levels. A 12-week strength training intervention performed on 40 nonathlete college students demonstrated similar increases in fat-free mass, with decreases in serum ferritin levels, in male subjects who started the training regimen with normal serum ferritin levels [45]. The authors of that training study suggested that the increase in training depleted iron stores, although this finding did not apply to their female athletes or participants (male or female) with low baseline serum ferritin levels [45].

Unlike serum $25-\mathrm{OH}$ vitamin $\mathrm{D}$, only the female athletes in the present study demonstrated significant relationships between serum ferritin $\Delta$ versus body composition variables (Figure 4). The directionality of these associations was also paradoxical, as increased serum ferritin levels across the competitive season were associated with decreased lean mass (Figure 4a) and increased body fat percent (Figure 4b). Decreased muscle mass and increased fat usually represent unfavorable training adaptations which signify overtraining, undertraining, under-recovery, or even under-nutrition with or without RED-S [20,22-24]. Although published studies clearly suggest that increased serum ferritin levels (from iron supplementation) enhance both endurance performance $[3,16]$ and strength gains [3], the physiological effects of serum ferritin levels on body composition markers requires more controlled investigations - including dietary and caloric intake data - particularly in female athletes participating in aesthetic and gravitational sports.

Preliminary associations between post-season athlete burnout with either serum 25$\mathrm{OH}$ vitamin $\mathrm{D}$ or serum ferritin levels (pre-season, post-season or $\Delta$ ) were not significantly correlated when all athletes were combined. However, when separated by sex, devaluation of sport (as a subscale) was negatively related to serum $25-\mathrm{OH}$ vitamin $\mathrm{D} \Delta$ while preseason serum ferritin was positively related to physical and emotional exhaustion in male athletes only. Previous studies have shown that 5-days of vitamin D3 enhances mood, when compared to placebo supplementation [4]. Similarly, a significant inverse relationship was documented between serum 25-OH vitamin D and depression scores in 615 healthy male and female University students (45.5ㅇ) [26]. Collectively, these studies suggest the possibility of a biopsychological link between mood and vitamin D. With regards to serum ferritin, a cross-sectional study performed on 192 female medical students found that serum ferritin levels were lower in depressed compared with non-depressed students [27]. Thus, a possible interplay between nutrient biochemistry and athlete burnout appears plausible and worthy of more critical follow-up in future, especially amongst male athletes.

Limitations: Changes in body composition (Table 2) and blood nutrient biomarkers (Figure 1) were perhaps too small (i.e. statistically and clinically insignificant) to make meaningful conclusions regarding optimal performance "thresholds" for serum 25-OH vitamin D and ferritin levels in athletes. Athletes with insufficient serum 25-OH vitamin $\mathrm{D}$ or ferritin at baseline (pre-season) were encouraged to ingest supplements at the counseling and recommendation of the team nutritionist (CA), but supplementation was never recorded. This lack of dietary evaluation, dietary supplement control, quantification of skin color and/or sunlight exposure compromised our ability to properly interpret the paradoxical relationships demonstrated between serum $25-\mathrm{OH}$ vitamin $\mathrm{D}$ and ferritin 
markers with body composition changes. The staggered endpoint for each sport (i.e. postseason testing) also offered additional confounding variables in interpreting relationships between nutrient biomarkers and body composition changes. Nonetheless, these preliminary results provide pilot data to launch more carefully controlled - and targeted - studies regarding the predictive utility of serum $25-\mathrm{OH}$ vitamin $\mathrm{D}$ and serum ferritin measurement on body composition and mood changes across a longer timeframe.

\section{Conclusions}

Serum 25-OH vitamin D levels declined in all athletes, regardless of indoor or outdoor sport, across the competitive season. The male athletes had lower $25-\mathrm{OH}$ vitamin $\mathrm{D}$ levels and increased burnout symptoms compared with female athletes. Conversely, serum ferritin levels increased across the season in both male and female athletes, with female athletes having lower serum ferritin levels compared with male athletes. The directionality of relationships between 25-OH vitamin D levels and total fat, lean and bone in male athletes were opposite of what was physiologically expected and largely driven by very low $25-\mathrm{OH}$ vitamin D levels in the male basketball players. Similarly, the directionality of relationships between serum ferritin levels and lean mass and fat percentage in female athletes were opposite of expected and paradoxically reflect a deleterious training response. Collectively, these results highlight the difficulties in creating "blanket" threshold recommendations for serum 25-OH vitamin D and ferritin levels to maximize body composition and mood changes across a variety seasons, sex and sports.

Our results also add caution to the utilization of single biomarkers - and nutrients to predict complex training outcomes favoring peak athlete health and performance. Additionally, the results from the present study question the current trend towards "biomarker creep" in sports performance. For example, the normal cut-off threshold for serum $25-\mathrm{OH}$ vitamin D in healthy individuals is $12 \mathrm{ng} / \mathrm{mL}$ while a threshold of $40 \mathrm{ng} / \mathrm{mL}$ is recommended for athletes seeking peak performance [2]. Similarly, the normal cut-off threshold for serum ferritin for healthy individuals is $12 \mathrm{ng} / \mathrm{mL}$ [19] while thresholds as high as $50 \mathrm{ng} / \mathrm{mL}$ have been recommended for male endurance athletes [15]. These elevated blood nutrient biomarker recommendations for athletes exist without compelling evidence, from randomized-control trials, which support enhanced physical or mental performance. Thus, elevated "athlete specific" thresholds for both serum $25-\mathrm{OH}$ vitamin $\mathrm{D}$ and serum ferritin requires further recalibration.

Author Contributions: All authors were involved with the development of this article and contributed to the following: conceptualization, THB, KLP, CA, BB, JM; Methodology, THB, KLP, CA, BB, GB; Formal Analysis, THB, JS, MV, VSH, BB, JM; Investigation, THB, KLP, CA, BB, GB; Data Curation, THB, KLP, CA, BB, GB; Writing - Original draft presentation, THB, VSH, MVS, JS; Funding acquisition, THB; Project administration, THB, KLP, CA, BB; Writing - Review and Editing, THB, $\mathrm{CA}, \mathrm{BB}, \mathrm{JS}, \mathrm{MV}$, VSH, KLP, GB, JM. All authors read and approved the final version of the manuscript and agreed with the order of presentation of the authors.

Funding: This research was funded by an internal Oakland University Prevention Research Center grant (THB).

Institutional Review Board Statement: The study was conducted according to the guidelines of the Declaration of Helsinki and approved by the Institutional Review Board (or Ethics Committee) of Oakland University (IRB\#778936, approval granted August 10, 2016).

Informed Consent Statement: Informed consent was obtained from all subjects involved in the study.

Data Availability Statement: All data will be available on request to the corresponding author (THB).

Acknowledgments: We wish to thank Barbara Ledin for laboratory assistance with biomarker analyses at Ascension/Crittendon Hospital and Lisa DeCeuninck, Christopher Ryan, and Justin Wight for lab assistance. We sincerely appreciate support from the cross country, swimming, basketball, and soccer coaches, staff, and players whose tenacity and enthusiasm inspired us both on and off the court. 
Conflicts of Interest: The authors declare no conflict of interest.

\section{References}

1. Schork, N.J. Personalized medicine: Time for one-person trials. Nature 2015, 520, 609-611, doi:10.1038/520609a.

2. Dahlquist, D.T.; Dieter, B.P.; Koehle, M.S. Plausible ergogenic effects of vitamin D on athletic performance and recovery. J Int Soc Sports Nutr 2015, 12, 33.

3. Pasricha, S.R.; Low, M.; Thompson, J.; Farrell, A.; De-Regil, L.M. Iron supplementation benefits physical performance in women of reproductive age: a systematic review and meta-analysis. J Nutr 2014, 144, 906-914, doi:10.3945/jn.113.189589.

4. Lansdowne, A.T.; Provost, S.C. Vitamin D3 enhances mood in healthy subjects during winter. Psychopharmacology (Berl) 1998, 135, 319-323, doi:10.1007/s002130050517.

5. Ljungqvist, A.; Jenoure, P.J.; Engebretsen, L.; Alonso, J.M.; Bahr, R.; Clough, A.F.; de Bondt, G.; Dvorak, J.; Maloley, R.; Matheson, G., et al. The International Olympic Committee (IOC) consensus statement on periodic health evaluation of elite athletes, March 2009. Clin J Sport Med 2009, 19, 347-365, doi:10.1097/JSM.0b013e3181b7332c.

6. Rockwell, M.; Hulver, M.; Eugene, E. Vitamin D Practice Patterns in National Collegiate Athletic Association Division I Collegiate Athletics Programs. J Athl Train 2020, 55, 65-70, doi:10.4085/1062-6050-21-19.

7. Parks, R.B.; Hetzel, S.J.; Brooks, M.A. Iron Deficiency and Anemia among Collegiate Athletes: A Retrospective Chart Review. Med Sci Sports Exerc 2017, 49, 1711-1715, doi:10.1249/mss.0000000000001259.

8. Grieshober, J.A.; Mehran, N.; Photopolous, C.; Fishman, M.; Lombardo, S.J.; Kharrazi, F.D. Vitamin D Insufficiency Among Professional Basketball Players: A Relationship to Fracture Risk and Athletic Performance. Orthop J Sports Med 2018, 6, 2325967118774329, doi:10.1177/2325967118774329.

9. Villacis, D.; Yi, A.; Jahn, R.; Kephart, C.J.; Charlton, T.; Gamradt, S.C.; Romano, R.; Tibone, J.E.; Hatch, G.F., 3rd. Prevalence of Abnormal Vitamin D Levels Among Division I NCAA Athletes. Sports Health 2014, 6, 340-347, doi:10.1177/1941738114524517.

10. Fields, J.B.; Payne, D.C.; Gallo, S.; Busteed, D.R.; Jones, M.T. Vitamin D Status Differs by Sex, Sport-Season, and Skin Pigmentation among Elite Collegiate Basketball Players. Sports (Basel) 2019, 7, doi:10.3390/sports7110239.

11. Fields, J.B.; Gallo, S.; Worswick, J.M.; Busteed, D.R.; Jones, M.T. 25-Hydroxyvitamin D, Vitamin D Binding Protein, Bioavailable 25-Hydroxyvitamin D, and Body Composition in a Diverse Sample of Women Collegiate Indoor Athletes. J Funct Morphol Kinesiol 2020, 5, doi:10.3390/jfmk5020032.

12. Weber, A.E.; Bolia, I.K.; Korber, S.; Mayfield, C.K.; Lindsay, A.; Rosen, J.; McMannes, S.; Romano, R.; Tibone, J.E.; Gamradt, S.C. Five-Year Surveillance of Vitamin D Levels in NCAA Division I Football Players: Risk Factors for Failed Supplementation. Orthop J Sports Med 2021, 9, 2325967120975100, doi:10.1177/2325967120975100.

13. Halliday, T.M.; Peterson, N.J.; Thomas, J.J.; Kleppinger, K.; Hollis, B.W.; Larson-Meyer, D.E. Vitamin D status relative to diet, lifestyle, injury, and illness in college athletes. Med Sci Sports Exerc 2011, 43, 335-343.

14. Cowell, B.S.; Rosenbloom, C.A.; Skinner, R.; Summers, S.H. Policies on screening female athletes for iron deficiency in NCAA division I-A institutions. Int J Sport Nutr Exerc Metab 2003, 13, 277-285, doi:10.1123/ijsnem.13.3.277.

15. Cook, J.D.; Skikne, B.S. Iron deficiency: definition and diagnosis. J Intern Med 1989, 226, 349-355, doi:10.1111/j.13652796.1989.tb01408.x.

16. Eichner, E.R. Perennial questions: on fatigue, on iron, and on anemia. Curr Sports Med Rep 2012, 11, 274-275, doi:10.1249/JSR.0b013e318272bbe0.

17. Pilch, W.; Kita, B.; Piotrowska, A.; Tota, Ł.; Maciejczyk, M.; Czerwińska-Ledwig, O.; Sadowska-Krepa, E.; Kita, S.; Pałka, T. The effect of vitamin D supplementation on the muscle damage after eccentric exercise in young men: a randomized, control trial. J Int Soc Sports Nutr 2020, 17, 53, doi:10.1186/s12970-020-00386-1. 
18. Miller, J.R.; Dunn, K.W.; Ciliberti, L.J., Jr.; Patel, R.D.; Swanson, B.A. Association of Vitamin D With Stress Fractures: A Retrospective Cohort Study. J Foot Ankle Surg 2016, 55, 117-120.

19. Risser, W.L.; Lee, E.J.; Poindexter, H.B.; West, M.S.; Pivarnik, J.M.; Risser, J.M.; Hickson, J.F. Iron deficiency in female athletes: its prevalence and impact on performance. Med Sci Sports Exerc 1988, 20, 116-121, doi:10.1249/00005768198820020-00003.

20. Barakat, C.; Pearson, J.; Escalante, G.; Campbell, B.; De Souza, E.O. Body Recomposition: Can Trained Individuals Build Muscle and Lose Fat at the Same Time? Strength \& Conditioning Journal 2020, 42, 7-21, doi:10.1519/ssc.0000000000000584.

21. Bennell, K.L.; Malcolm, S.A.; Khan, K.M.; Thomas, S.A.; Reid, S.J.; Brukner, P.D.; Ebeling, P.R.; Wark, J.D. Bone mass and bone turnover in power athletes, endurance athletes, and controls: a 12-month longitudinal study. Bone 1997, 20, 477-484, doi:10.1016/s8756-3282(97)00026-4.

22. Stanfa, M.R.; Silles, N.N.; Cooper, A.; Arena, S.; Landis-Piwowar, K.; Aprik, C.; Hew-Butler, T. Risk Factors for Collegiate Swimmers Hospitalized With Exertional Rhabdomyolysis. Clin J Sport Med 2017, 27, 37-45.

23. Mountjoy, M.; Sundgot-Borgen, J.; Burke, L.; Carter, S.; Constantini, N.; Lebrun, C.; Meyer, N.; Sherman, R.; Steffen, K.; Budgett, R., et al. The IOC consensus statement: beyond the Female Athlete Triad--Relative Energy Deficiency in Sport (RED-S). Br J Sports Med 2014, 48, 491-497, doi:10.1136/bjsports-2014-093502.

24. Tenforde, A.S.; Carlson, J.L.; Chang, A.; Sainani, K.L.; Shultz, R.; Kim, J.H.; Cutti, P.; Golden, N.H.; Fredericson, M. Association of the Female Athlete Triad Risk Assessment Stratification to the Development of Bone Stress Injuries in Collegiate Athletes. Am J Sports Med 2017, 45, 302-310, doi:10.1177/0363546516676262.

25. Scheid, J.L.; Stefanik, M.E. Drive for Thinness Predicts Musculoskeletal Injuries in Division II NCAA Female Athletes. J Funct Morphol Kinesiol 2019, 4, doi:10.3390/jfmk4030052.

26. Polak, M.A.; Houghton, L.A.; Reeder, A.I.; Harper, M.J.; Conner, T.S. Serum 25-hydroxyvitamin D concentrations and depressive symptoms among young adult men and women. Nutrients 2014, 6, 4720-4730. Vahdat Shariatpanaahi, M.; Vahdat Shariatpanaahi, Z.; Moshtaaghi, M.; Shahbaazi, S.H.; Abadi, A. The relationship between depression and serum ferritin level. Eur J Clin Nutr 2007, 61, 532-535, doi:10.1038/sj.ejcn.1602542. Holick, M.F.; Binkley, N.C.; Bischoff-Ferrari, H.A.; Gordon, C.M.; Hanley, D.A.; Heaney, R.P.; Murad, M.H.; Weaver, C.M. Evaluation, treatment, and prevention of vitamin D deficiency: an Endocrine Society clinical practice guideline. J Clin Endocrinol. Metab 2011, 96, 1911-1930.

29. Nielsen, P.; Nachtigall, D. Iron supplementation in athletes. Current recommendations. Sports Med 1998, 26, 207-216, doi:10.2165/00007256-199826040-00001.

30. Hologic. QDR Reference Manual, MAN-00732 Revision 002 ed.; Hologic, Inc: Bedford, MA, 2007.

31. Raedeke, T.D.; Smith, A.L. Development and Preliminary Validation of an Athlete Burnout Measure. J Sport Exerc Psychol 2001, 23, 281-306, doi:10.1123/jsep.23.4.281.

Sullivan, G.M.; Feinn, R. Using Effect Size-or Why the P Value Is Not Enough. J Grad Med Educ 2012, 4, 279-282, doi:10.4300/jgme-d-12-00156.1.

Wilson-Barnes, S.L.; Hunt, J.E.A.; Williams, E.L.; Allison, S.J.; Wild, J.J.; Wainwright, J.; Lanham-New, S.A.; Manders, R.J.F. Seasonal variation in vitamin $\mathrm{D}$ status, bone health and athletic performance in competitive university student athletes: a longitudinal study. J Nutr Sci 2020, 9, e8, doi:10.1017/jns.2020.1.

34. Constantini, N.W.; Arieli, R.; Chodick, G.; Dubnov-Raz, G. High prevalence of vitamin D insufficiency in athletes and dancers. Clin J Sport Med 2010, 20, 368-371.

35. Powe, C.E.; Evans, M.K.; Wenger, J.; Zonderman, A.B.; Berg, A.H.; Nalls, M.; Tamez, H.; Zhang, D.; Bhan, I.; Karumanchi, S.A., et al. Vitamin D-binding protein and vitamin D status of black Americans and white Americans. N. Engl. J Med 2013, 369, 1991-2000.

36. Lewis, R.M.; Redzic, M.; Thomas, D.T. The effects of season-long vitamin D supplementation on collegiate swimmers and divers. Int J Sport Nutr. Exerc Metab 2013, 23, 431-440. 
37. Webb, A.R.; Kline, L.; Holick, M.F. Influence of season and latitude on the cutaneous synthesis of vitamin D3: exposure to winter sunlight in Boston and Edmonton will not promote vitamin D3 synthesis in human skin. J Clin Endocrinol. Metab 1988, 67, 373-378.

38. Klesges, R.C.; Ward, K.D.; Shelton, M.L.; Applegate, W.B.; Cantler, E.D.; Palmieri, G.M.; Harmon, K.; Davis, J. Changes in bone mineral content in male athletes. Mechanisms of action and intervention effects. JAMA 1996, 276, 226-230.

39. Heller, J.E.; Thomas, J.J.; Hollis, B.W.; Larson-Meyer, D.E. Relation between vitamin D status and body composition in collegiate athletes. Int J Sport Nutr Exerc Metab 2015, 25, 128-135, doi:10.1123/ijsnem.2013-0250.

40. LeFevre, M.L.; LeFevre, N.M. Vitamin D Screening and Supplementation in Community-Dwelling Adults: Common Questions and Answers. Am Fam Physician 2018, 97, 254-260.

41. Jin, J. Screening for Vitamin D Deficiency in Adults. Jama 2021, 325, 1480, doi:10.1001/jama.2021.4606.

42. Camaschella, C. Iron deficiency. Blood 2019, 133, 30-39, doi:10.1182/blood-2018-05-815944.

43. Kell, D.B.; Pretorius, E. Serum ferritin is an important inflammatory disease marker, as it is mainly a leakage product from damaged cells. Metallomics 2014, 6, 748-773, doi:10.1039/c3mt00347g.

44. Comassi, M.; Vitolo, E.; Pratali, L.; Del Turco, S.; Dellanoce, C.; Rossi, C.; Santini, E.; Solini, A. Acute effects of different degrees of ultra-endurance exercise on systemic inflammatory responses. Intern Med J 2015, 45, 74-79, doi:10.1111/imj.12625.

45. Deruisseau, K.C.; Roberts, L.M.; Kushnick, M.R.; Evans, A.M.; Austin, K.; Haymes, E.M. Iron status of young males and females performing weight-training exercise. Med Sci Sports Exerc 2004, 36, 241-248,

doi:10.1249/01.Mss.0000113483.13339.7b. 